\title{
Feldpostbriefe aus dem Zweiten Weltkrieg — zur möglichen Bedeutung im aktuellen Meinungsstreit unter besonderer Berücksichtigung des Themas "Antisemitismus"
}

Wilhelm Deist schrieb 1991 als Leitender Historiker des Militärgeschichtlichen Forschungsamtes in einem Rückblick auf 30 Jahre Weltkriegsforschung:

"Auf ein Defizit der Forschung sei an dieser Stelle nachdrücklich hingewiesen. Wie der Soldat an der Front in der Masse und unter der Führung des Regimes diesen Krieg erfuhr und welche Wirkungen davon ausgingen, bleibt eine Fragestellung, mit der sich die Forschung erst punktuell auseinandergesetzt hat. Angesichts der ca. 20 Millionen Wehrmachtangehöriger, die prägende Jahre ihres Lebens in den Streitkräften verbrachten und als Kriegsgeneration den Aufbau der Bundesrepublik bestimmten, bedarf die Forderung nach systematischen Untersuchungen wohl keiner besondéren Rechtfertigung 1 .«

Der Hinweis von Deist ist in den vergangenen Jahren von mehreren Autoren aufgegriffen worden. Feldpostbriefe generell, speziell aber die des Zweiten Weltkrieges, waren Gegenstand beachteter Veröffentlichungen ${ }^{2}$. Der Verfasser des vorliegenden Beitrages hat sich diesem Thema auf der Basis der Briefe von 25 Wehrmachtsoldaten der Jahrgänge 1901 bis 1923 zugewandt, die sie zwischen Juni 1941

1 Wilhelm Deist, Der deutsche Angriff auf die Sowjetunion, in: Ders., Militär, Staat und Gesellschaft. Studien zur preußisch-deutschen Militärgeschichte, München 1991 (= Beiträge zur Militärgeschichte, Bd 34), S. 369 f.

2 Anstöße für die Erforschung der Feldpost des Zweiten Weltkriegs gab zunächst Peter Knoch, Feldpost - eine unentdeckte historische Quellengattung, in: Geschichtsdidaktik, 11 (1986), H. 2, S. 154-171; Kriegsalltag. Die Rekonstruktion des Kriegsalltags als Aufgabe der historischen Forschung und der Friedenserziehung, hrsg. von Peter Knoch, Stuttgart 1989. In den 90er Jahren folgten militärhistorische Studien, die explizit die Feldpostbriefe zum Ausgangspunkt nahmen: Stalingrad. Mythos und Wirklichkeit einer Schlacht, hrsg. von Wolfram Wette und Gerd R. Ueberschär, Frankfurt a.M. 1992; Andere Helme - andere Menschen? Heimaterfahrung und Frontalltag im Zweiten Weltkrieg. Ein internationaler Vergleich, hrsg. von Detlef Vogel und Wolfram Wette, Essen 1995 (= Schriften der Bibliothek für Zeitgeschichte, N.F., Bd 2). Schließlich zwei Dissertationen über Feldpostbriefe des Zweiten Weltkrieges (weitere Literaturangaben dort): Martin Humburg, Das Gesicht des Krieges - Feldpostbriefe von Wehrmachtsoldaten aus der Sowjetunion 1941-1944, Wiesbaden 1998; Klaus Latzel, Deutsche Soldaten - nationalsozialistischer Krieg?, Paderborn 1998. Anhaltendes öffentliches Interesse an der Quelle "Feldpostbrief « dokumentiert zur Zeit auch das in deutscher Übersetzung aus dem Amerikanischen erschienene Buch: Stephen G. Fritz, Hitlers Frontsoldaten. Der erzählte Krieg, Berlin 1998 [Orig. 1995]. In der anschaulich geschriebenen Zusammenstellung mischen sich Feldpostbriefe, Tagebücher, Memoiren, mündliche Berichte - alle übernommen aus der Sekundärliteratur ohne eine Differenzierung der Quellen und deren Aussagewert - zu einem thematisch gegliederten Kaleidoskop von Eindrücken, die wohl oft zutreffen, manchmal aber auch beliebig bleiben und manchmal auch in die Irre führen (so die Schlußfolgerungen auf das höhere Bildungsniveau der deutschen Soldaten aufgrund des Briefstils, der aber in den herkömmlichen Sammlungen auf ein nicht repräsentatives Auswahlverfahren `aussagekräftiger`, 'gehaltvoller ‘ Briefe zurückgeht, vgl. S. 18), wie schon der Titel kaum seine Rechtfertigung finden kann angesichts der weitgehenden Unklarheit über die jeweiligen Einsatzorte der zitierten Soldaten. 
und Spätsommer 1944 aus dem Krieg gegen die Sowjetunion schrieben. 739 Briefe wurden aus den ca. 25000 Briefen der »Sammlung Sterz (Bibliothek für Zeitgeschichte, Stuttgart) ausgewählt nach dem Kriterium, daß Dokumente von denselben Soldaten über einen längeren Zeitraum vorhanden sind, um deren Entwicklungen nachzeichnen zu können.

$\mathrm{Zu}$ den Schreibern konnten in vielen, nicht allen Fällen biografische Daten gewonnen werden, so daß ihr sozialer Hintergrund erkennbar wird. Untersucht wurden Entwicklungen ausgewählter Themen in Abhängigkeit von der Zeit (vier definierte Zeitabschnitte zwischen Juni 1941 und Herbst 1944)³, dem Alter (jüngere/ältere) und dem Dienstgrad (Mannschaften/Unteroffiziere). Für spezielle Fragen wurden weitere Differenzierungen vorgenommen. So konnten die "Aufsteiger " (von Mannschafts- zu Unteroffiziersgrad) mit den "Nicht-Aufsteigern «, bzw. Soldaten bei kämpfenden Einheiten mit solchen im Nachschub verglichen werden. Soweit möglich, wurden auch soziale Herkunft sowie Zuordnungen zu militärischen Einheiten (frontnahe und frontferne), bzw. jeweiliger Standort (Nord, Mitte, Süd) ermittelt, um Auswirkungen auf die Briefthemen systematisch zu erfassen ${ }^{4}$.

Eine nachprüfbare empirische Untersuchung von Themenverteilungen, die nicht nur selektiv vorgeht, sondern das gesamte Spektrum erfassen will, dient dem Ziel, über Zufallsbefunde und die weit verbreitete eklektische Methode der Zitatenauswahl im Dienste der einen oder anderen Theorie hinauszukommen. Dabei soll ein erster quantifizierender Zugriff nicht darüber hinwegtäuschen, daß die Menge der Aussagen zu einem bestimmten Thema allein ein unzureichendes Indiz für die Bedeutung dieses Themas für den Schreiber wäre. Gerade heikle Themen - alle, die im weitesten Sinne mit einem Tabu belegt sind - können mit seltenen, dafür aber aussagekräftigen und den Schreiber charakterisierenden Bemerkungen angesprochen werden. Und bei manchen Themen wird viel eher als ihre häufige Nennung ihre Abwesenheit interessieren - auch diese erschließt sich zweifelsfrei aber nur einer quantitativen Erfassung. In dem Verhältnis zwischen "allgemeinen «, »trivialen « Briefthemen und den »besonderen«, »aufschlußreichen « Mitteilungen wird man den Feldpostbrief als historische Quelle im Spannungsfeld zwischen Mitteilungsbedürfnis und (Selbst-)Zensur am ehesten angemessen gewichten können.

Die Briefe wurden auf der Basis eines Kategoriensystems mit ca. 90 Einzelthemen inhaltlich analysiert. Insgesamt wurden knapp 13000 Kategorisierungen (= Themenzuordnungen zu den einzelnen Sätzen/Aussagen) vorgenommen, die sich aber nicht gleichmäßig auf die Einzelthemen verteilen; vielmehr ragen zehn "Standardthemen" heraus, auf die etwa 33 Prozent (4376) aller Kategorisierungen entfielen. Bei einer separaten Prüfung auf Redundanzen - wie oft kommen dieselben Themen in demselben Brief vor - waren es ebenfalls diese zehn Themen, die einen Anteil von 72 Prozent an allen Redundanzen einnahmen: Es zeichnet den Feldpostbrief typischerweise aus, daß er die Adressaten der Zuneigung des Brief-

3 Dadurch gehen in die statistischen Auswertungen die Zeiträume von April bis September 1942 und April bis Juni 1943 nicht ein.

4 Zur Methode im einzelnen (Inhaltsanalyse, Kategoriensystem, Reliabilitätsuntersuchungen): Martin Humburg, Feldpostbriefe aus dem Zweiten Weltkrieg - Werkstattbericht zu einer Inhaltsanalyse, Internet: http:// hsozkult.geschichte.hu-berlin.de (= Zeitschrift für historische Sozialforschung 1998). Zu Fragen der Repräsentativität: Humburg, Gesicht des Krieges (wie Anm. 2), S. 81 f. 
schreibers versichern soll; daß er sie beruhigen soll über dessen Lage, womit sich der Soldat gleichzeitig im Schreiben selbst auch beruhigt. Der Feldpostbrief hat die Aufgabe, mit der Empfangsbestätigung und dem Hinweis auf eigene abgesandte Post das poröse Band der Kommunikation zu stabilisieren. Aus dem Erleben des Soldaten sind es eher "triviale«, gleichwohl für ihn existentiell wichtige Themen wie das Wetter und der alltägliche Trott, über die er schreibt, auch in dem Bewußtsein, daß diese Themen am ehesten kommunizierbar sind, weil sich die Angehörigen darunter etwas vorstellen können. Schließlich prägen die Sehnsucht nach Heimkehr und die Bitte um konkrete Hilfssendungen viele Briefe.

Mit leichten Verschiebungen ist dieses Bild auch innerhalb der vier Zeitabschnitte der Untersuchung dasselbe. Im Winter 1941/42 treten das Klima, vor allem Kälte, Frost und Schnee, und die Sorge um den Transport der Feldpost stärker hervor; im letzten Kriegsjahr ragt die Bekräftigung der Zuneigung noch mehr heraus. Bis auf diese wenigen und auch recht plausiblen Verschiebungen kann man im Hinblick auf die wenigen herausragenden Standardthemen von einer großen Konstanz in der Briefkommunikation ausgehen. Auch der Vergleich zwischen den Untergruppen auf der Basis gleicher Briefmengen und -längen ergibt, daß die Präferenz dieser Standardthemen bei den Schreibern verschiedenen Dienstgrades und Alters sowie in Eltern- und Partnerschaftsbriefen weitgehend identisch ist.

Einige Unterschiede zeigen aber aufschlußreiche Tendenzen: Betrachtet man den Anteil, den die Standardthemen einnehmen, so liegt er bei den Mannschaftssoldaten höher als bei den Unteroffizieren (etwa $30 \mathrm{zu} 25$ Prozent). Die Mannschaftssoldaten schreiben also - bei insgesamt kürzeren Briefen - z.B. relativ häufiger über das Wetter, den Dienstalltag, über die Postsendung, und die jüngeren unter ihnen sehen sich noch eher gehalten, die Eltern zu beruhigen, als es in den Partnerschaftsbriefen geschieht.

Bemerkenswert ist auch ein anderer Vergleich: Während die Unteroffiziere etwa im Verhältnis $60 \mathrm{zu} 40$ längere Briefe schreiben als die Mannschaftssoldaten, ist es bei den Redundanzen umgekehrt. Das Verhältnis beträgt etwa 35 zu 65 Prozent - die Mannschaftssoldaten wiederholen sich auf weniger Raum deutlich häufiger. Berücksichtigt man die für diese Stichprobe geltende weitgehende Koinzidenz von höherem Dienstgrad und höherer sozialer Schicht, so kann man in diesem Ergebnis ein Indiz für die höhere Schreiberfahrung und -sicherheit der Unteroffiziere sehen. Die Themenbreite, über die sie verfügen, läßt sie weniger angewiesen sein auf die "Standardthemen «, und wo sie diese ansprechen, tun sie es konzentrierter als die Mannschaftssoldaten. Die schichthöheren Soldaten schreiben überdies syntaktisch komplexer (parataktische Fügungen statt einfacher Reihungen) und sind auch in der Rechtschreibung sicherer als die anderen.

Ein nicht-triviales Thema, bei dem überdies der Grad des Abstands zwischen Zeitgenossen und Nachgeborenen durchaus ständig neu zur Diskussion stehen kann, ist die gedankliche und die praktische Teilhabe der Wehrmachtsoldaten am Antisemitismus ihrer Zeit. Können Feldpostbriefe hier überhaupt zur Aufklärung beitragen oder markiert gerade dieses Thema eine Grenze für den Wert der Feldpostbriefe als historische Quelle?

Aktive Beteiligung der Wehrmacht an Verbrechen gerade im Ostkrieg erscheint heute unter Fachleuten unstrittig, was den Dissens über die Breite der Beteiligung und die Repräsentativität von Einzelereignissen keineswegs ausschließt. Mit Blick auf die Wehrmacht, der »eigentlichen Schnittstelle von >Volksgemeinschaft<, NS-Re- 
gime und Expansion $\aleph^{5}$ erscheint es nach Förster als »schlichtweg falsch, weiterhin anzunehmen, nur Hitlers Weltanschauungstruppen, die Einsatzgruppen der Sicherheitspolizei und des SD, Ordnungspolizeibataillone und Waffen-SS Brigaden, hätten nach dem 22. Juni 1941 begonnen, Juden und Kommunisten in großem Stil zu erschießen «. Vielmehr war auch die Wehrmacht »ein williger Vollstecker Hitlerscher Ziele " ${ }^{6}$. "In bezug auf den Holocaust agierte die Wehrmacht in verschiedenen Rollen: Sie war Täter, Helfer, Mitwisser und Zuschauer.« Gleichsam einen Gegenpol zu einer pauschalisierenden Verurteilung der einzelnen Wehrmachtangehörigen stellt der Hinweis auf die Möglichkeit von »Unbehagen, Widerspruch, ja sogar Widerstand $\ll^{7}$ im Einzelfall dar. Hans-Erich Volkmann faßt für den Partisanenkrieg zusammen:

"Gemäß der von Hitler geprägten Formel, Partisan gleich Jude, ließ sich die Wehrmacht in das Verbrechen des rassischen Vernichtungskrieges hineinziehen. Die Partisanenkriegführung artete in Exzesse gegen die Zivilbevölkerung unter Einschluß von Frauen und Kindern sowohl in Italien wie in Südosteuropa aus, pervertierte aber auf dem Balkan und auf sowjetischem Territorium zur politisch gewollten rassischen Ausmerze, an der sich die Wehrmacht durch entsprechende eindeutige Befehle und durch Beteiligung an Mordaktionen mitschuldig machte 8 ."

$\mathrm{Da}$ die Wehrmacht dabei kein »monolithischer Block" war" zeigt z.B. die von Major v. Gersdorff im August 1941 anläßlich einer Frontinspektion berichtete allgemeine Ablehnung im Offizierkorps von »Erschießungen der Juden, der Gefangenen und auch der Kommissare", wobei er gleichzeitig feststellte, daß »die vorhandenen Tatsachen in vollem Umfang bekannt geworden sind « ${ }^{10}$.

Wolfram Wette hat einmal in pointierter Gegenrede zu apologetischen Versuchen die Verantwortung der Wehrmacht so benannt:

"Es geht aber gerade darum - zum Beispiel im Hinblick auf den Holocaust festzuhalten, daß es die Wehrmacht war, die durch ihre Befehle und ihre Soldaten die Judenvernichtung praktisch in Gang gesetzt hat. [...] Wenn ich die Opferzahlen zusammenrechne - fünf Millionen Zivilisten, anderthalb Millionen Juden, dreieinhalb Millionen Kriegsgefangene --, dann kommt dabei als schreckliche Summe mehr heraus, als alle SS-Männer in Auschwitz und an anderen Orten ermordet haben ${ }^{11} \cdot \ll$

Er weist das Argument, daß die Soldaten der Wehrmacht als Frontsoldaten davon nichts mitbekamen, weil sich die Verbrechen in den rückwärtigen Gebieten abgespielt hätten, mit dem Hinweis zurück, daß das Verhältnis zwischen Fronttruppen

5 Jürgen Förster, Wehrmacht, Krieg und Holocaust, in: Die Wehrmacht. Mythos und Realität, hrsg. von Rolf-Dieter Müller und Hans-Erich Volkmann, München 1999, S. 948. Zur Vertiefung siehe insbesondere die Beiträge unter Kap. VI: Die Wehrmacht als Teil des NS-Unrechtsstaates. Raul Hilberg, Wehrmacht und Judenvernichtung, in: Die Wehrmacht im Rassenkrieg, hrsg. von Walter Manoschek, Wien 1996, S. 23-38.

6 Förster, Wehrmacht (wie Anm. 5), S. 953.

7 Ebd., S. 963.

B Hans-Erich Volkmann, Zur Verantwortlichkeit der Wehrmacht, in: Die Wehrmacht (wie Anm. 5), S. 1206.

9 Ebd., S. 1207; siehe auch Timm C. Richter, Die Wehrmacht und der Partisanenkrieg in den besetzten Gebieten der Sowjetunion, in: Die Wehrmacht (wie Anm. 5), S. 837-857.

10 Nach Richter, Wehrmacht, ebd., S. 848.

11 Wolfram Wette, im Zeit-Gespräch: »Wir hatten geglaubt, wir könnten anständig bleiben«. Die Zeit, Nr. 10, 3.3.1995, S. 16. 
und Etappentruppen den Zahlen nach ungefähr eins zu sechs war und das rückwärtige Heeresgebiet ungefähr 80 Prozent, das Frontgebiet nur ca. 15 bis 20 Prozent des gesamten Heeresgebietes umfaßte.

Aktive Beteiligung, indirekte Zuarbeit, Mitwissen ohne eigene Beteiligung, Nichtbeteiligung und Nichtwissen: zwischen diesen unterschiedlichen Verhaltensformen erstreckt sich ein breites Spektrum von Nähe und Distanz gegenüber den verbrecherischen Anteilen des Krieges. Es liegt also nahe, Zeitzeugen - im zivilen und militärischen Bereich - zu ihren Kenntnissen darüber zu hören - besser noch: deren Zeugnisse aus jener Zeit zu befragen, die noch nicht von dem Nachkriegswissen geprägt sind.

Zeugnisse aus dem zivilen Bereich seien vorangestellt, um dann zu Zeitzeugnissen aus dem militärischen Bereich zu kommen:

Der Direktor des Niederländischen Reichsinstituts für Kriegsdokumentation Louis de Jong belegt minutiös anhand der Reaktionen des Amsterdamer Judenrates die "völlige und fatale Fehlinterpretation « bis weit ins Jahr 1942 von allen Meldungen über die Ermordung von deportierten holländischen Juden in Auschwitz ${ }^{12}$. Weitere Beispiele von holländischen Inhaftierten in Auschwitz, die wieder frei kamen, u.a. 6 Frauen der Zeugen Jehovas, zeigen das immer wiederkehrende Phänomen: "Die meisten Leute weigerten sich, uns zu glauben ${ }^{13}$. « De Jong führt als Gründe die strenge Geheimhaltung, die ausgefeilten Täuschungen (z.B. Briefe von Deportierten an ihre Angehörigen) und vor allem die völlige Unvereinbarkeit des Geschehens mit allem bisher Vorstellbaren an. "Die ganze Sache überstieg so sehr die menschliche Vorstellungskraft, daß unser Verstand die Tatsachen, wenn er sie einmal erfaßt hat, gleich wieder ausspuckt als etwas äußerst Fremdes und widernatürlich Ekelhaftes ${ }^{14}$. « Aus der zeitlichen Eingrenzung de Jongs darf man rückschließen, daß aber mit Ablauf des Jahres 1942 die Tatsachen nicht mehr zu leugnen waren.

Auch für einen der kritischen und genauen Zeitzeugen wie Victor Klemperer bleibt es immer wieder in der Schwebe, in welchem Verhältnis bei den »Ariern « in seiner Umgebung Gleichgültigkeit, Mitwisserschaft und Akeptanz gegenüber antisemitischen Maßnahmen stehen ${ }^{15}$. Er selbst hat erste Kenntnis von Auschwitz »als furchtbarstes KZ « seit März $1942^{16}$. Aber immer wieder beschreibt er »die Ahnungslosigkeit im Punkt des Judenelends « bei seinen Zeitgenossen ${ }^{17}$.

»Eigentümlich und mir unerklärlich, wie in den Regierungsmaßnahmen der öffentliche Terror der Abschreckung und die geheime Grausamkeit Hand in Hand gehen. Gegen die Juden wird maßlos gehetzt - aber die schlimmsten Maßnahmen gegen sie werden vor den Ariern verheimlicht. Selbst nahestehende Leute kennen weder die kleinen Schikanen noch die grausigen Morde ${ }^{18}{ }_{\text {. }}$ So kommt Klemperer bei allem Zorn auf die großen und kleinen Täter doch nicht zu einem pauschalen Urteil gegenüber den Deutschen. Seine Einzelbeobachtun-

12 Louis de Jong, Die Niederlande und Auschwitz, in: Vierteljahrshefte für Zeitgeschichte, 17 (1969), S. 1-16.

13 Ebd., S. 11.

14 Ebd., S. 15.

15 Victor Klemperer, Ich will Zeugnis ablegen bis zum letzten. Tagebücher 1933-1945, 2 Bde, Berlin 1995.

16 Ebd., 16.3.1942, Bd 2, S. 47.

17 Ebd, 19.4.1942, Bd 2, S. 66.

18 Ebd., 30.1.1943, Bd 2, S. 324. 
gen registrieren sowohl die durchschlagende Wirkung der Propaganda wie auch die Angst — "das stärkste Gefühl im Volke « ${ }^{19}$.

Stellvertretend für eine rückschauende Aussage sei Marion Gräfin Dönhoff zitiert. Selbst dem Widerstand des 20. Juli nahestehend und somit durch Mitglieder des Kreisauer Kreises informiert, gibt sie an, daß sie den Namen Auschwitz erst nach dem Krieg zum erstenmal gehört habe. "Man wußte, die Leute werden weggeschafft in den Osten. Aber daß es keine Arbeitslager, sondern Vernichtungslager waren, das habe ich erst nach dem Krieg erfahren. Auf die Idee, daß alle umgebracht werden, konnte kein Mensch kommen.« Doch »daß ganze Dörfer aus Rache massakriert wurden, von diesen Greueltaten wußte man " und gerade diese Beobachtungen gaben auch Angehörigen der Wehrmacht den Anstoß, sich dem Widerstand zuzuwenden ${ }^{20}$.

Was sagen nun Briefe von »einfachen Soldaten « aus? Geben sie Aufschluß über Grad und Breite der Beteiligung am rassenpolitischen Konzept der Nationalsozialisten? Und wenn schon nicht im Sinne einer Tatenbeschreibung, die man sich unter den Bedingungen der Zensur kaum vorstellen kann, so doch in Form der sideologischen Flankierung ، durch abwertende, antisemitische Äußerungen?

Nach Goldhagen ${ }^{21}$, der von einem »eliminatorischen Antisemitismus« der Deutschen ausgeht, müßte das Verhältnis zu den Juden auch in den Feldpostbriefen ein durchaus präsentes Thema sein - und es dürfte, zumindest in der Affirmation des antisemitischen Denkens auch nicht unter das Verbot der Zensur oder Selbstzensur fallen, wenn ein Soldat sich darüber mit den Eltern oder der Partnerin austauschen wollte.

Zunächst auch hier ein Blick in vorausgehende Forschungsbefunde, bei denen man das Bemühen um seinschlägige Zitater mit dem Ziel beobachten kann, die These und Erkenntnis von den, Verbrechen der Wehrmacht nun gleichsam mit Basisquellen von beteiligten Tätern zu untermauern.

Darion Dömhoff. Ein widerständig.

D̈̈r wir konnten anstandig bleiben «. Die Zeit Nr. 10, 3.3.1995, S. 18. Vgl. allgemein zum Wissen in der Zivilbevölkerung: "Niemand war dabei und keiner hat's gewußt. « Die deutsche Öffentlichkeit und die Judenverfolgung 1933-1945, hrsg. von Jörg Wollenberg, München 1989.

21 Daniel J. Goldhagen, Hitlers willige Vollstrecker, Berlin 1996. Vgl. die Debatte dazu: Julius H. Schoeps, Ein Volk von Mördern? Die Dokumentation zur Goldhagen-Kontroverse um die Rolle der Deutschen im Holocaust, Hamburg 1996; Wolgang Wippermann, Wessen Schuld? Vom Historikerstreit zur Goldhagen-Kontroverse, Berlin 1997. Der Spiegel, Nr. 33/1997, S. 156-158 und Nr. 34/1997, S. 56-62 zu Norman Finkelsteins Kritik an Goldhagen in New Left Review, Juli/August 1997. Christopher Browning, Daniel Goldhagens willige Vollstrecker, in: Der Weg zur "Endlösung «, Bonn 1998, S. 161-182. Goldhagens These: 1. Die Zahl der Täter, die am Holocaust beteiligt waren, ist weit größer als bisher angenommen. Er schätzt sie auf 100000 bis $1 / 2$ Million Deutsche, unterstützt von Hilfspersonal aus anderen Ländern. 2. Angesichts der willfährigen und selbstverständlichen Ausführung so zahlloser Mordaufträge - nicht nur in den Lagern, sondern eben auch im Kriegsalltag, bei Deportationen und Todesmärschen - kann als Motiv im Kern nur eine bereitwillige, bejahende Grundhaltung zum Massenmord angenommen werden; alle weiter differenzierenden Gründe mögen eine Rolle spielen, reichen aber zur Erklärung nicht aus. 3. Dies vorausgesetzt, muß es bei den Deutschen eine Disposition - eine über Jahrhunderte zurück verfolgbare Spur eines »eliminatorischen Antisemitismus « - geben, der nicht nur Ablehnung, sondern Vernichtung der Juden in sich birgt und den Massenmord an den Juden nicht als Tat weniger Verbrecher, sondern als »ein nationales Projekt« der Deutschen erscheinen läßt. 
Volker Ullrich greift u.a. auf einzelne Feldpostbriefe aus der "Sammlung Sterz" zurück, die vom Wissen um »Ghettos«, Massenerschießungen, "Entjudung " von Ortschaften zeugen ${ }^{22}$. Auch das Wissen von der systematischen Massenvernichtung war nach Ullrich weiter verbreitet, als es spätere Beteuerungen wahrhaben wollen. Deportationen fanden öffentlich und am hellen Tage statt; Auschwitz war ein Verkehrsknotenpunkt, den auch viele Urlauber passierten, die sich über brennende Schlote und süßlichen Geruch wunderten. So verfügten viele über Teilinformationen; es hätte aber einer Bereitschaft bedurft, diese zu einem Gesamtbild zusammenzusetzen. Stattdessen war die häufigste Reaktion, übrigens auch bei den Gegnern, "das unerhört Schreckliche, die Wahrheit über den Genozid, nicht wahrhaben zu wollen, sondern sie abzuwehren und zu verdrängen $\aleph^{23}$.

Walter Manoschek hat in dem Heft »Es gibt nur eines für das Judentum: Vernichtung ${ }^{24} \mathrm{ca} .100$ Passagen aus Feldpostbriefen, vorwiegend aus Südost- und Osteuropa, zusammengestellt, die auf den Antisemitismus der deutschen Soldaten und ihre willfährige Beteiligung am Völkermord schließen lassen sollen. So verdienstvoll es ist, unter diesem Gesichtspunkt Einzelzitate zusammenzustellen, so viele Fragen wirft diese Edition gleichzeitig auf.

1. Es fehlt jede inhaltliche Gewichtung: Krasse Äußerungen »Vor allen Dingen muß der Jude ausgemerzt werden ${ }^{25}$ lassen im Einzelfall an der antisemitischen Ausrichtung keinen Zweifel. Andere Formulierungen, die eher beschreiben, ja sogar Distanz zur Politik gegenüber den Juden ausdrücken - $\gg$ Hier sind auch alle Juden zusammengepfercht [...] Ich möchte kein Jude sein. Zu diesem Kapitel könnte ich Euch noch mehr schreiben ${ }^{26}$. — - gehen eher unter und werden ebenfalls nicht in einen Zusammenhang gestellt. Der Leser bleibt allerdings mit einer Suggestion von einem weit verbreiteten extremen Antisemitismus zurück.

2. Manoschek bedient sich der Vorarbeiten von Sterz, der zu seiner umfangreichen Sammlung (insgesamt ca. 50000 Briefe gesichtet, 25000 in Stuttgart erhalten) eine Stichwortkartei angelegt hat, die auf seine maschinenschriftlichen Exzerpte verweist. Nach meiner Einschätzung dieser Quellenaufbereitung wird man die Inhalte der Zitate als weitgehend korrekt betrachten können, es schleichen sich allerdings im Detail Fehler ein, was gerade bei diesem sensiblen Thema einen Rückgriff auf die (meist vorhandenen) Originalbriefe geboten erscheinen läßt. Manoschek gibt selbst durch die Gegenüberstellung von Originalkopie und Briefexzerpt einige, wohl unfreiwillige Beispiele für die Abweichungen und damit für sein recht zügiges Vorgehen, wenn er die Exzerpte als die originalen Quellen ausgibt ${ }^{27}$.

3. Manoschek verkürzt, evtl. mit Rücksicht auf die Anonymität, die bei Sterz vollständig genannten Namen auf die Initialen. Damit entzieht er dem Leser die

Volker Ullrich, »Wir haben nichts gewußt« - Ein deutsches Trauma, in: 1999. Zeitschrift für Sozialgeschichte des 20. und 21. Jahrhundert, 6 (1991), H. 4, S. 11-46.

Ebd., S. 33.

Walter Manoschek, »Es gibt nur eines für das Judentum: Vernichtung. « Das Judenbild in deutschen Soldatenbriefen 1939-1944, Hamburg 1995.

Gefr. M.F., am 23.7.1941, ebd., S. 37.

Gefr. G.R., am 27.4.1941, ebd., S. 21.

Ebd., S. 23 f. 44 f., 64 f. und 76 f. Um Mißdeutungen vorzubeugen: Dies schränkt den Quellenwert der Sterz-Exzerpte nur unwesentlich ein, sie behalten in ihrer Aussage Gültigkeit; der Forscher, der sich ihrer bedient, ist aber gehalten, seine Zitate daraus als Exzerpte (Sterz) kenntlich zu machen und nur dann als Original-Brief-Zitate auszugeben, wenn er den Abgleich vorgenommen hat. 
Kenntnis, daß es sich recht häufig um die Zitate jeweils derselben Briefschreiber handelt; die 100 Einzelstellen verteilen sich also auf eine deutlich kleinere Zahl verschiedener Schreiber.

4. Dies macht das eigentliche Defizit einer solchen eklektischen Quellenzusammenstellung deutlich: es wird die Chance vertan, Entwicklungen über die Zeit zu dokumentieren: Entstehung und Verhärtungen von Einstellungen, aber auch deren Relativierung, erschließen sich, wenn überhaupt, in der Abfolge mehrerer Briefe derselben Schreiber. Bei allen Fragen, die die Juden betreffen, wird man auch das Ausbleiben dieses Themas nur im systematischen Blick in alle Briefe einer definierten Auswahlstichprobe zutreffend gewichten können.

5. In meiner Untersuchung von 739 Feldpostbriefen aus der Sowjetunion zwischen 1941 und 1944 finden sich in ca. 2 Prozent Aussagen, die das Thema Juden ausdrücklich betreffen. Bis auf drei fallen alle Aussagen dazu in die ersten Kriegswochen bis Ende September $1941^{28}$. Geht man bei den Sterz-Exzerpten realistischerweise einmal von nur 8000 bis 10000 durch Sterz auf diese Stichworte durchgesehenen Briefe aus, so entsprächen Manoscheks 100 Zitate zum Thema "Juden und Antisemitismus « etwa den 1-2 Prozent, die auch in meiner Studie ermittelt werden. Auch in der zeitlichen Gewichtung gibt es eine Entsprechung, wenn knapp die Hälfte (44) von Manoscheks Zitaten aus dem Jahr 1941 stammen und sich die anderen auf die Jahre 1939 und 1942 bis 1944 verteilen.

Manchem mögen solche Quantifizierungen zu detailverliebt erscheinen, das völlige Fehlen derartiger Einordnungen bei Manoschek suggeriert aber ein falsches Bild.

Den Versuch, auf der Basis von Feldpostbriefen eine Affinität der Wehrmachtsoldaten zum Antisemitismus im Sinne des Nationalsozialismus nachzuweisen, unternimmt auch Omer Bartov ${ }^{29}$. Er greift dabei allerdings zurück auf eine zeitgenössische, von Wolfgang Diewerge im Auftrag des Reichspropagandaamtes herausgegebene Schrift mit dem Titel »Deutsche Soldaten sehen die Sowjetunion. Feldpostbriefe aus dem Osten «. Zwar erkennt Bartov die ideologische Absicht der Zusammenstellung, sieht aber »keinen Grund, die Authentizität der darin abgedruckten Briefe anzuzweifeln, zumal sie inhaltlich den nach dem Krieg zusammengetragenen Briefen vergleichbar sind $\ll^{30}$.

Ich teile diese Argumentation aus folgenden Gründen nicht:

1. Die Wahrscheinlichkeit der Fälschung, zumindest der starken Retusche ist anhand einer anderen populären Briefsammlung - "Letzte Briefe aus Stalingrad", auf die sich Bartov übrigens auch unkritisch bezieht, herausgearbeitet worden ${ }^{31}$.

2. Der Zweifel an der Repräsentativität, ja sogar Echtheit der Briefe wird genährt gerade durch die Unterschiedlichkeit im Tonfall und die ideologische Schärfe der sumstrittenen، Feldpostbriefe im Vergleich zu snormalen، Briefen. Genauere Lek-

28 über die Zivilov über die Zivilbevölkerung im besetzten Land gehen hierin nicht ein; siehe dazu: Humburg, Gesicht des Krieges (wie Anm. 2), S. 151-155.

29 ges, Reinbek 1995.

30

31

Ebd., S. $233-249$ und Anm. 144, S. 308.

Jens Ebert, Zwischen Mythos und Wirklichkeit. Die Schlacht um Stalingrad in deutschsprachigen authentischen und literarischen Texten. Unveröff. Diss. Berlin 1989. Ebert bezweifelt aus seiner Kenntnis von Originalbriefen aus Stalingrad die Authentizität der „Letzten Briefe«. 
türe der Passagen, die Bartov aus Diewerge zitiert, zeigen eine viel schärfere, auf 'Ausmerzung ‘ und Vernichtung der Juden gerichtete Sprache, als in den authentischen Briefen; zwar gibt es solche extreme Schreibweisen auch in den Sammlungen authentischer Briefe, sie stellen dort aber nur eine unter recht verschiedenen Weisen der ideologischen Argumentation der Soldaten dar. So entsteht bei Bartov ein zu monolithisches Bild, ganz im Sinn seiner These von der ideologisch durchdrungenen Wehrmacht. Etwas anderes aber bleibt bemerkenswert an einer Ausgabe wie der von. Diewerge: die Offenheit des Vokabulars, mit dem $1941 \mathrm{dem}$ Judenmord das Wort geredet wird. Von Geheimhaltung der Absichten ist da nicht viel zu spüren, vielmehr von einem Versuch, das eigene radikale Vorgehen als $>\mathrm{Ge}-$ genwehr < oder $>$ Vorsorge zu rechtfertigen ${ }^{32}$.

Gestützt wird die Annahme eines breiteren öffentlichen Wissens über den Holocaust durch Ludwig Eiber ${ }^{33}$ : Beschrieben und in Auszügen dokumentiert werden die Briefe eines Bremer Kaufmanns, eines 'ganz normalen Familienvaters, Jahrgang 1902, an seine Frau. Er schreibt von seinem Einsatz beim Reserve-Polizeibataillon 105 in der Sowjetunion 1941. Es fällt auf, daß seine Briefe in vielem themengleich sind mit den Feldpostbriefen der Soldaten, mit einer Ausnahme: Er schreibt regelmäßig und ausführlich über Einsätze seiner Sondereinheit gegen Partisanen und Juden, über Zwangsrekrutierungen und Erschießungen. Trotz des Wissens um das Schweigegebot und den Tabubruch drängen sich ihm diese Ereignisse in die Briefe.

So sehr nun dieses Dokument eines Polizeiangehörigen einschlägig vom Wissen und Mithandeln des Schreibers Zeugnis ablegt, so wirft es doch für die Bewertung der Feldpostbriefe von Wehrmachtsoldaten, in denen solche deutlichen Passagen selten zu finden sind, die Frage nach der Interpretation dieses Unterschiedes auf. Denn Eibers Schilderungen zeigen ja, daß weder Zensur noch Selbstzensur mächtig genug sind, um ihn von der Weitergabe des ihn bedrängenden Wissens abzuhalten. Das weitgehende Fehlen solcher expliziten Äußerungen in den Briefen der Wehrmachtsoldaten ist vor diesem Hintergrund noch einmal stärker zu gewichten.

$\mathrm{Zu}$ dem Schluß einer weitgehenden Absenz des Themas Judenvernichtung kommt auch Klaus Latzel auf der Basis von 22 Briefserien aus dem Zweiten Welt$\mathrm{krieg}^{34}$. Fast bedauernd klingt es; daß trotz der erdrückenden historischen Belege "für die Zusammenarbeit zwischen Wehrmacht und SS sowohl in den höchsten Führungsstäben wie auch vor Ort sowie für selbständige Mordaktionen von Wehrmachteinheiten « konstatiert wird: »[diese Belege] finden sich nur nicht in meinem Quellenkorpus $\ll^{35}$. Die wenigen verstreuten Einzelinformationen, die »verschiedene Elemente des Aussonderungs-, nicht aber des Vernichtungsprozesses " erwähnen, werfen nur »Schlaglichter « ohne den Zusammenhang, in den die einzelnen Beobachtungen einzuordnen wären. Latzel schlußfolgert als Parallele zwischen der deutschen Bevölkerung im Ganzen und den Soldaten im Kleinen, daß »ein, wahrscheinlich weitverbreitetes Wissen von Einzelteilen der Praxis der Judenver-

32 Humburg, Gesicht des Krieges (wie Anm. 2), S. 55-59. Vgl. dazu auch: Klaus Latzel, Wehrmachtsoldaten zwischen "Normalität « und NS-Ideologie, oder: Was sucht die Forschung in der Feldpost?, in: Die Wehrmacht (wie Anm. 5), S. $577 \mathrm{f}$.

33 Ludwig Eiber, "...ein bisschen die Wahrheit «, in: 1999. Zeitschrift für Sozialgeschichte des 20. und 21. Jahrhundert, 6 (1991), H. 1, S. 58-83.

${ }_{34}$ Latzel, Deutsche Soldaten (wie Anm. 2), S. 201-205.

35 Ebd., S. 202. 
folgung und -vernichtung existierte, ohne daß diese Einzelheiten sich zum Gesamtbild 'Endlösung r rundeten. Wieviel im Einzelfall die hier zitierten Soldaten und auch diejenigen, die zum Thema schwiegen, davon wußten, muß offen bleiben ${ }^{36}$."

Nun zu der eigenen Untersuchung. Das Thema "Juden" wird in 15 von 739 Briefen (ca. 2 Prozent) überhaupt erwähnt, und zwar von 10 der 25 Soldaten. Die anderen erwähnen es in der Briefauswahl nicht ${ }^{37}$. Bis auf drei fallen alle Äußerungen in die ersten Kriegswochen bis zum 24. September 1941.

Daß die Aussagenmenge nur ein erster Zugang zur Interpretation ist und kein hinreichendes Kriterium, um die Einstellung des Schreibers zu ermessen, zeigt das Beispiel von Erich Leismeier ${ }^{38}$, Jahrgang 1922, Gebirgs-Panzer-Jäger Abt. 44 (Süd). In den Briefen an seine Mutter präsentiert er sich als lebenslustiger, wagemutiger Draufgänger, der gar nicht schnell genug an die Front kommen kann ${ }^{39}$.

"[...] Eins fürchten wir ja alle: daß wir zu spät nach vorne kommen, viel ist ja sowieso nicht mehr übrig. In dieser Stadt findet man nur wenig Spuren des Krieges, wo Widerstand war, ging eben der Laden hoch; das haben ja inzwischen unsere lieben Feinde einsehen müssen! [...] Grüßt mir alle Freunde und Freundinnen von mir, dem zackigen Gebirgspanzerjäger, aus dem Feindesland herzlichst.« [4.8.1941]

Zwei Wochen später seine einzige Äußerung zu Juden in den hier untersuchten 23 Briefen:

»Die vielen hundert Kilometer, die wir nun zurückgelegt haben, zeigten uns die Härte und Grausamkeit dieses Kampfes. Es ist mir nicht möglich, das alles im Einzelnen zu schildern, aber hier geht es wirklich um Sein oder Nichtsein. Je tiefer wir nach Rußland vorfuhren, um so mehr trafen wir auf Juden. Die Kerle sind noch genau so frech wie im tiefsten Frieden. Man sollte eigentlich noch viel mehr dieser Ausgeburten an die Wand stellen, als bisher geschehen ist. « [17.8.1941]

Bemerkenswert ist nicht nur die bruchlose Übernahme des in diesem Falle tatsächlich eliminatorischen Antisemitismus, sondern auch die Selbstverständlichkeit, mit der er das nach Hause schreibt. Aber die Schreibhaltung verändert sich, wird angesichts der Kämpfe und der Toten nachdenklicher. Immer hin- und hergerissen zwischen den Rollen als mutiger Soldat und vorsichtiger Sohn erklärt er schließlich einmal seine gefahrvolle Kradmeldertätigkeit und markiert zugleich eine vorsichtige Schreibhaltung für die Zukunft, nicht ohne noch mal den Stolz anzumelden:

»Vom neuen Einsatz werde ich Dir genau so wenig berichten, Du würdest Dich noch mehr um mich sorgen. Aber oft wird es halt nur zu einem Kärtchen mit

Ebd., S. $203 \mathrm{f}$

Aufgrund der Auswahl von Zeitabschnitten von Juni 1941 bis Spätsommer 1944 gehen in diesen Befund die Monate April bis September 1942 und April bis Juni 1943 nicht ein. Der kursorische Blick in die Briefe der Stichprobe aus den hier nicht statistisch erfaßsten Zeiträumen hat bisher die folgenden Befunde nicht in Frage gestellt.

38 Die Namen der Briefschreiber aus der Sammlung Sterz sind anonymisiert, eine Liste zur Identifizierung liegt in der Bibliothek für Zeitgeschichte (Stuttgart) vor. Darüber hinaus verwandte Briefe sind mit Vornamen und abgekürztem Nachnamen zitiert.

39 Vgl. zur Entwicklung vom Optimismus zur Skepsis bei diesem Soldaten: Martin Humburg, Siegeshoffnungen und »Herbstkrise« im Jahre 1941 - Anmerkungen zu Feldpostbriefen aus der Sowjetunion, in: Feldpostbriefe - Grüße von der Front. Werkstatt Geschichte, 22 (1999), S. 25-40. 
wenigen Worten reichen, Du weißt dann, was los ist, weißt aber auch, daß das Unkraut, das bekanntlich nicht verdirbt, auch noch nicht verdorben ist.

Nun, liebe Mutti, frage mich bitte nicht mehr, ich habe es versucht, Dir für Deine Begriffe es klar zu machen, vor allem aber deshalb, damit Du nicht etwa glaubst, ich sei gar ein Etappenhengst, dazu bin ich mir zu gut und zu jung. « [10.2.1942]

Wieweit er mit der Judenfrage keine Berührung mehr hatte oder ob dieses Thema nun auch unter die Selbstzensur fällt, läßt sich nicht klären.

Eine solche Neigung, der Zensur und der Vorsicht vor den Reaktionen der heimischen Adressatin Gewicht beizumessen, finden wir bei Ludwig Bumke aus München, Jahrgang 1908. Als Kraftfahrer im motorisierten Nachschubbataillon 563 (156. Infanterie-Division) ist er Ende Juni 1941 noch in Krakau, kommt dann aber bald nach Rußland, wo er bis 1943 vor allem im Süden eingesetzt ist.

Er ist anfangs so vorsichtig, mit seiner Frau einen Buchstabencode zu vereinbaren, aus der sie seinen gegenwärtigen Aufenthaltsort ermitteln kann, »denn es ist das verboten den Standort zu schreiben [...] Es wäre nicht das erste Mal, daß Briefe geöffnet würden!!« [16.9.1941]

$\mathrm{Daß}$ er aber auch hoch sensibel auf die besorgten Nachfragen aus der Heimat reagiert, zeigt eine Klimax der 'Angstvorbeugung:

"Wenn mehrere Tage keine Post kommt, keine Angst, sind in einem Wald, wo keine Post geht.« [1.7.1941]

"Letztens war Dein Brief reichlich schwarzsehend. Aber es ist doch absolut kein Grund dazu. Zum Angst haben, ist doch gar kein Grund vorhanden, wenn wirklich mal einige Tage keine Post kommt.« [10.8.1941]

Wie bekommst Du eigentlich meine Post, den Nummern nach oder durcheinander, es kann sein, daß es noch länger dauert, wenn es weiter nach Osten geht! Also keine Angst.« [16.8.1941]

"Wenn Du dich trotzdem, daß ich Dir schon xmal geschrieben habe, daß bei uns, wo wir eben immer sind, genau so viel das heißt genau so wenig vom Krieg zu hören, sondern nur einige hundert Kilometer hinterher zu sehen ist, kann ich Dir wahrhaftig nicht mehr helfen. Wenn du diese vollkommen grundlose Angsthaberei nicht aufgibst, werde ich mal etwas unzünftig. Es ist fast das Gleiche, als würde ich dauernd Angst haben, englische Flieger kämen nach München. Solange wir hier sind haben wir (in der Luft) noch kein russisches Flugzeug gesehen!! [25.8.1941]

Lassen wir vor seinen Äußerungen zu den Juden noch weitere Nuancen in den Briefen zu Wort kommen, sie zeigen ihn einerseits als jemanden, der sein Urteil ganz pragmatisch nach seinen leiblichen Erlebnissen bildet, andererseits als jemanden, der sich in den politischen Zusammenhängen zurechtfinden will und schließlich zu einer bemerkenswert heftigen Kehrtwende gelangt:

1940, im Jahr der `Erfolge < ist er ganz auf Optimismus gestimmt:

„Wenn wir gleich fortkommen, glauben wir, als Wachablösung wohin zu kommen. Man ist halt zwischen Hoffnung und Vermutung. [...] Jeder sucht sich schon ein Land aus, in das er zur Besatzung hinzukommen wünscht. Ich habe mir Dänemark ausgesucht, weil es dort viel Butter gibt.« [25.5.1940]

Und seine Träume gelten der Nachkriegszeit und dem kleinen Wohlstand, wenn er auch gegen die Bedrohung der Hoffnung anschreiben muß:

"Unsere Volkswagennummer haben wir, infolge dessen gehören wir zu den ersten, die ihn bekommen. Deshalb ist Deine Freude nicht ins Wasser gefallen. Aufgeschoben ist nicht aufgehoben.« [14.7.1940] 
"Die Kriegssparer werden auf jeden Fall nicht enttäuscht, sondern belohnt werden, hat Wirtschaftsminister Funk einmal gesagt. [...] Vielleicht bekommen wir nach dem Krieg einen Anhänger dazu geschenkt, als Belohnung für unser Sparen!« [25.10.1941]

Er ist, wie er am 30. März 1941 schreibt, seit 1. August 1930 Mitglied in der NSDAP - aber er stellt sein Urteil nicht dauerhaft unter die Vorgaben der Partei. Zwar orientiert er sich zunächst noch am »Führer", aber wie er es tut, klingt weniger devot als fordernd:

"Hast schon nach der Rede des Führers gefragt, in der er gesagt hat, daß dieses Jahr die Entscheidung fällt. Wenn Du sie nicht eigens bekommst, dann siehst mal nach in einem Buch, das die gesamten Kriegsreden des Führer enthält. (Man kann es in italienischer Sprache haben, dann wird mans auch in deutscher bekommen.) Wir wollen es, weil davon verständlicher Weise oft gesprochen wird, von höchster Stelle wissen, ob er nun doch noch heuer aus wird. Ich bin nun satt, bis über beide Ohren.« [21.8.1941]

Im Winter 1941/42 erlebt er seine Wende, wieder ausgehend von der eigenen sinnlichen Erfahrung:

»Heute kamen auch Wintersachen, aber weitaus zu wenig! Man mußte erst fragen, wer hat żum Beispiel eigene Handschuhe, der bekommt wahrscheinlich keine. Auch bei uns macht sich der Mangel an Spinnstoffwaren beträchtlich bemerkbar. Obwohl man doch Zeit genug hatte, bis der Winter kam. « [7.12.1941] Als er im Frühjahr 1942 hört, daß der kleine Sohn in seine Fußstapfen treten will, ist seine Reaktion alles andere als die eines stolzen Vaters, er hat schon genug erlebt:

"Er will auch schon Soldaten spielen. Ich hab gesagt, ich hau ihm den Arsch, wenn ich heimkomme, von wegen Soldaten spielen.« [4.3.1942]

Aber seine Stimmung wird noch bitterer, seine brieflichen Urteile noch galliger, als die Bombardierungen der Heimat zunehmen und vor allem nach dem Fall von Stalingrad. Angesichts seiner anfänglichen Besorgtheit wegen der Zensur fällt der Wandel um so krasser auf:

"Ja, die Geschädigten, besonders die die Tote haben, wissen was es bedeutet, wenn Goebbels voriges Jahr sagte, es käme nicht darauf an, wie lange der Krieg dauere, wohl aber, daß wir siegen. Freilich ist es keinem egal, wie seine Zukunft ist, aber keiner kann es einem andern verübeln, wenn er sagt, daß er froh ist, wenn der Krieg aus ist. Das sage ich Jedem, sei es, wer es auch wolle.« [20.12.1942]

"Auf der Landkarte Pläne entwerfen, wäre eben nur dann von vollem Erfolg, wenn es überall so wäre wie in Frankreich. Anderer Meinung zu sein, hieße eben die Rchng. ohne den Wirt machen, das haben wir im Kaukasus in vollem Ausmaß erfahren müssen, genau so, wie Napoleon vor $130 \mathrm{Jhr}$. Auch er hat gemeint, er könne alles auf einmal machen, zu bedauern sind nur solche, die die Prellböcke einer solchen Nimmersattpolitik sind, z.B. die $46000 \mathrm{Ge}-$ fangenen der 6. Armee von Stalingrad. Das hätte man vermeiden können: wenn man dem Kaukasus noch die Ruhe gelassen hätte. Aber wenn einer ein Geschäft gleich zu groß haben will, nimmt Geld über die Aussichten seiner künftigen Einnahmen auf, macht er schneller pleite, als er es vorher geahnt hat. So ging es auch uns, weil wir weder zum Kriegführen noch zum Verwalten genügend Menschen haben. [...] Was nützen uns die großen Gebiete, wenn wir die eigene Heimat dadurch nicht mehr genügend schützen können.« [16.3.1943] 
"Ja, von dem Angriff hab ich, wie ich schon geschrieben habe, von einem Kd. gehört. Habe aber nicht gedacht, daß er so schlimm gewesen wäre. $152 \mathrm{Op}-$ fer sind keine Kleinigkeit. Ja, Herr Dr. Goebbels, es kommt nicht darauf an, wie lange der Krieg dauere?! « [24.3.1943]

Wie sind vor diesem Hintergrund die wenigen Äußerungen zu deuten, die Bumke über Juden macht?

Den Einsatz in Polen erfährt er zunächst als Bestätigung eines Weltbildes, das er vorher aus zweiter Hand kannte, und er mag sich als Angehöriger der überlegenen Wehrmacht auch in dem alltäglichen, hier gönnerhaft ausgestalteten Gestus des Herrenmenschen einrichten. Aus Cholm schreibt er:

"Ich hab mir schon einmal Brot gekauft, um wenigstens satt zu bekommen. Die Frau von dem Wirt hat den Kopf geschüttelt, wie kann man nur trockenes Brot essen. Obwohl die Polenkinder vor unserem Fenster herumlaufen, >bitte Herr Brot: Sie beißen auch tatsächlich mit einem seltenen Appetit, von dem ihnen vom Fenster auf den Boden geworfenen Stück Brot. Jetzt kommt man doch dahinter, daß es genauso ist, wie es die Zeitungen und der Rundfunk immer geschildert haben. Ja teilweise sogar schlimmer, denn den Dreck kann man ja nicht mit auf ein Bild bringen. Wenn ich abends so durch die Straßen gehe, bekomme ich immer einen bestimmten Geruch in die Nase, den ich sonst nirgends fand, als in der Wohnung unseres ehem. jüdischen Kunden Lindauer.«.[1.3.1942]

Drei Monate später macht er, eingestreut in ein Idyll aus dem »Generalgouvernement", seine Frau mit dem Wort "Ghetto" bekannt, das er für erklärungsbedürftig hält. Er geht also von ihrer Uninformiertheit über solche Lager aus.

"Mir würde es hier in Krakau sehr gut gefallen. Wohl die schönste Stadt des G.G. Krakau hat sehr schöne Parkanlagen, schöne moderne Häuser. Ist nicht umsonst die Hauptstadt des G.G. Man sieht hier so wenig Juden mehr, daß man sie zählen könnte, die Straßenbahnen haben kein Judenabteil mehr. Sie sind alle in ein Ghetto gekommen (Judenviertel). In zirka 10 Jahren, wenn Krakau erst noch besser ausgebaut ist, glaube ich, möchte ich auch da sein.« [20.6.1941]

Im August bleibt unklar, ob er selbst ein Ereignis miterlebte oder sich auf einen anderen Bericht bezieht, als er über ein Lemberger Vorkommnis schreibt; seine Frau scheint dadurch beunruhigt.

"Das mit den Juden, das heißt dem einen in Lemberg, das war ja in einem Cafe, was soll da passieren, Du stellst Dir alles, was wir hier erleben xmal tragischer vor, als es ist. Ich weiß, daß alles, bis es in die Heimat kommt, von der Mücke zum Elefant wird. Glaube nicht alles, was oft reichlich übertrieben ist.« [10.8.1941] Funktioniert so das Lernen, was der Soldat lieber für sich behält? Vielleicht hatte er über ein Ereignis in einem Lemberger Cafe geschrieben (ein entsprechender Brief ist nicht vorhanden). Mit der Weigerung, genauer auf ihre Frage zu antworten, erteilt er eine pauschale Belehrung, wie sie mit Nachrichten, die nicht ins gewünschte Bild passen, umgehen soll. Der äußeren Zensur, die er umgehen will, fügt er von sich aus eine Binnenzensur hinzu, die regelt, was zu dem Thema gefragt werden darf. Möglicherweise ist der Ausschnitt auch ein Beleg für die Veränderung der eigenen Schreibhaltung - nach einer offenen Schilderung in einem vorausgegangenen Brief erfährt er durch die Fragen der verunsicherten Frau, daß er zu leichtfertig etwas beschrieben hat, was er jetzt wieder zurücknehmen will ${ }^{40}$.

40 Zu Pogromen im Raum Lemberg im Juli 1941: Bernd Boll, Das Grab in der Zitadelle. Der Judenmord in Zlocow vom Juli 1941 und die Rolle der Wehrmacht. Frankfurter Rundschau, Nr. 187 vom 14.8.1999, S. 20. 
Nur in zwei weiteren Notizen erwähnt er Juden, und zwar eher beiläufig. Immerhin geht es ihm jetzt wesentlich um die Rechtfertigung und die Abgrenzung von anderen Soldaten, bei denen sich die Normen dessen, was erlaubt ist, schon weiter verschoben haben, als bei ihm. Seine Äußerungen markieren einen Grenzgang zwischen heimischen Normen, die er mit seiner Frau teilt, und den Normen der jetzt für ihn relevanten Bezugsgruppe der Soldaten, aus deren Rahmen er auch nicht herausfallen möchte:

»Vorgestern kamen wir vom Kommando zurück, heute hören wir schon, daß denen, die uns abgelöst haben, die Hälfte der 250 Gefangenen abgehauen sind, weil sie oft geschlagen wurden. Es sind durchweg ganz junge Kerle, die wahrscheinlich gleich ganz vorne waren und deshalb gleich als Erste gefangen wurden. Drei davon sprachen fließend deutsch, dem einen seine Urgroßmutter war aus D., dem anderen seine Mutter aus Hamburg, der Dritte ist Jude. Sie haben sich gewundert, daß sie von uns gut behandelt wurden, was einem, von verschiedenen verübelt wird. Man kann das auch verstehen, wenn man mit Verwundeten spricht, die mit eigenen Augen mit ansehen mußten, wie unsere Leute bestialisch ermordet wurden. Aber wir konnten in diesen Gefangenen die Beobachtung machen, daß ein vernünftiges Wort auch solche verhetzte Menschen wieder zurückführen kann zu einem normalen Menschen.« [16.8.1941]

Während er bei den ersten beiden deutschsprechenden Gefangenen ihre Beziehung zur deutschen Herkunft herstellt, kommt ihm das bei dem Juden nicht in den Sinn. Aber das ist in diesem Fall die einzige Unterscheidung, der die (von ihm angegebene) gute Behandlung gegenübersteht $t^{41}$. Unabhängig davon, wie wenig harmonisch man sich den Fortgang dieser Begegnung vorstellen muß, bleibt bemerkenswert, welches Bild der Soldat hier im Brief an die Frau von sich und seinem Kommando zeichnen will.

Bumkes letzte Äußerung in diesem Zusammenhang klingt schon fast wie eine Standardformulierung der Propaganda, die er aus dem Rundfunk oder einer Zeitung übernommen haben kann:

"Aber Hauptsache, daß es vorwärts geht. Und ich glaube, daß es vorwärts geht, denn der Sowjetjude Maysky hat schon einen Hilferuf um Panzer an London gerichtet.« [24.9.1941]

Man kann in den Zitaten wohl nur eine sehr bedingte Zustimmung zum Menschenbild des Nationalsozialismus erkennen; denn auch der vorsichtige Versuch einer Abgrenzung klingt an, wenn er die Einteilung der Menschen nicht als statisch ansieht. Allerdings ist er weit entfernt von einer Widerständigkeit gegenüber dem vorherrschenden Umgang mit den Juden, wie er sie im Hinblick auf die NSFührungsriege zumindest verbal schon mal riskiert ${ }^{42}$.

41 Der »Zentralrat der deutschen Juden « mußte 1935 seinen Namen ändern in »Zentralrat der Juden in Deutschland«, da Juden nicht mehr deutsch sein konnten (siehe Die Zeit, Nr. 34 vom 19.8.1999, S. 3 - Nachruf auf Ignaz Bubis). Bumke hat mit seiner Formulierung entweder diese Ausgrenzung verinnerlicht oder er findet es keiner besonderern Begründung wert, daß ein Jude in Galizien des Deutschen mächtig ist.

42 An dieser Stelle sei hingewiesen auf den bisher unausgewerteten Briefbestand des Heinrich Roth (Orig.-Name), Jahrgang 1903, in der Sammlung Sterz: Bei diesem Angehörigen der 383. Inf. Div. (389. Nachschubkompanie, später Bau-Pionier Batl. 735, Raum Charkow und Dünaburg) fällt ein Grundton der zunehmend heftigeren Kritik an der eigenen Führung auf, die sogar Hitler nicht ausspart. Anlaß ist ihm nicht nur die schlechter werdende eigene Lage, sondern auch das Morden, das er beobachtet. Vgl. Humburg, Gesicht des Krieges (wie Anm. 2), S. 108 f. 
Ähnlich ist auch bei anderen Soldaten zu beobachten, daß sie kein selbstverständliches negatives Bild der "slawischen Massen" pflegen; vielmehr unterscheiden sie oft bei aller Verachtung für die russische Unkultur zwischen der armen Zivilbevölkerung, die zwar als ängstlich und mißtrauisch, aber des öfteren auch als "freundlich", "nicht feindlich gesinnt" geschildert wird, und den "Machthabern «, die für alles Schlechte verantwortlich gemacht werden. Aber ihre Mitteilungen dazu bleiben knapp, mit verächtlichem Unterton gegen »Bolschewismus « und "Kommunismus", die zwar (eher aufzählend) mit Juden assoziiert genannt werden; der Antisemitismus selbst wird aber nicht explizit geäußert:

"Je weiter wir kommen, je mehr merkt man die kommunistischen Verhältnisse. Trostlos, wie diese Menschen hier hausen. Da ist es bei uns Gold dagegen. Wir machen gerade eine kleine Rast am Ortseingang, eben marschierte eine Kompanie Juden v vorbei unter deutscher Aufsicht zum Straßenreinigungsdienst. Hier hat es mehr Juden wie andere." [Erwin Jolz, 2. Kp Bau-Btl. 402, in Litauen, 27.6.1941]

»Die Kultur des Bolschewismus spiegelt sich im Land. Elend und Not wird unser Auge sehen wie bisher. Doch das richtige Bild wird man sich erst machen können, wenn man erst mal eine große Stadt sehen wird dort erst kommt die rechte Feinheit zur Beurteilung. Sehr rosig soll es nicht aussehen nach Aussagen eines Flüchtlings der hier aufgegriffen wurde und das Volk würde uns erwarten die Juden sollen schon ausgerückt sein u.s.w. mehr. " [Alfred Vilsen, 2. Fahrschwadr. Nachschub Tr. 36, 36. Inf. Div., bei Pleskau (Nord), 5.8.1941] Deutlicher schon sucht der Obergefreite Hans Sulzer (Jahrgang 1919) Belege für Klischees: "Ich bin jetzt ungefähr da wo Vater im letzten Krieg stand. Der Ort in dem wir sind wimmelt voll Juden. Nur 1/3 der Bevölkerung sollen Polen sein. Wie es da aussieht kannst Du dir sicher vorstellen. Die allgemeine Not verstehen diese bettelnden Hyänen auszunutzen. Die Preise sind furchtbar hoch.

Verschiedentlich habe ich schon festgestellt, daß die Russen den Juden nicht gut gesinnt sind. Die Frau in unserem Quartier sagte z.B.: Ruski Kartoschki, Juden Konfekt, Schokolad. Das heißt: die Russen müssen das ganze Jahr Kartoffeln essen während die Juden das ganze Jahr von Schokolade und Konfekt leben.«

[Hans Sulzer, 22.6.1941 (Raum Shitomir) und 6.1.1942 (Raum Brjansk/Orel)] In den Briefen des einzigen Mitglieds der Waffen-SS in dieser Gruppe findet sich insgesamt nur eine, dafür allerdings eindeutige antisemitische Außerung. Der 23jährige Erich Nürnbach șchreibt an seine Eltern:

"Von der Beschädigung der Talsperre habe ich im Wehrmachtbericht gehört. Die Wut kann sich keiner vorstellen, welche die Landser bei solchen Dingen kriegen. Wenn wir nur den Briten allein hätten, dann sähe ich schwarz für ihn! Im Ubrigen wurde dieser feige Angriff auf die Talsperren von emigrierten Juden, welche mit der betreffenden Gegend vertraut waren, angezettelt. Vielleicht ist sogar von denselben Judas einer früher einmal in einem heute durch den Wassersturz zerstörten Dorf mit Koffern herumgezogen und hat mit seinem Schundzeug die Leute betrogen! Über die sogenannte 'humane Kriegführung unserer Feinde, die wir ja eigentlich lieben sollten, gibt's überhaupt nichts mehr zu reden. Hoffentlich sehen nun auch bald die letzten Querköpfe ihre falschen Ansichten ein.« [4.6.1943]

Nürnbach läßt der offiziös angeregten Gerüchtebildung also im Gewande der Feindkritik eine Rechtfertigung jeder Radikalisierung folgen:

"Entweder wir werden diesen Krieg gewinnen oder es wird eine andere Welt - ohne uns geben! Das Letztere kommt sowieso auf keinen Fall infrage, das 
wird uns die Zeit lehren!« [4.6.1943] »Es ist das Wichtigste, den Feind zu vernichten, damit wir vor ihm eine Ruhe haben.« [8.6.1943] »Daß der Krieg entsprechend seiner bisherigen Dauer hart ist, ist eine logische Folge und, wenn man ehrlich ist, so hat man sich auch daran schon gewöhnt. Leider, und das ist ja auch schon oft geschrieben worden, trifft es unsere Zivilbevölkerung. Für einen Soldaten ist das nicht recht passend, da doch nach seiner Meinung nach der Krieg eine Sache der Männer ist. Nur zu deutlich sieht man an dieser Art Kriegführung, mit was für einer Sorte man es zu tun hat. Aber jeder neue Angriff dieser Terroristen ist ein sicherer Garant dafür, daß, wenn einmal der große Tag der Vergeltung kommt, Auge um Auge und Zahn um Zahn ohne Rücksicht auf Kinder und Greise vergolten wird mit gleichen Waffen. Diese Auffassung und bestimmte Meinung trägt jeder Soldat in sich und das mit jedem Tag mehr. Gnade Gott — England!! « [28.7.1943]

Was das konkret für sein eigenes Kriegshandeln heißt, beschreibt er zwar nicht. Die Frage drängt sich aber auf, ob er das, was er den Engländern für die Zukunft ankündigt, bereits in Südrußland (Charkow, Stalino) gegenüber der dortigen Zivilbevölkerung, insbesondere deren jüdischen Teilen, selbst erlebt hat und damit auch nachträglich rechtfertigen will.

Soweit rekonstruierbar, sind die bisher zitierten Soldaten eher dem soziokulturellen Milieu der unteren Mittelschicht zuzuordnen; sie (bzw. ihre Väter) sind Handwerker, Landwirte, kleine Beamte. Leismeier, Sulzer und Nürnbach haben eine Aufstiegsorientierung, die korrespondiert mit einem insgesamt elaborierteren Schreibstil.

Argumentativ ausführlicher äußern sich Angehörige der oberen Mittelschicht und des Bildungsbürgertums. So sind, wenn überhaupt, bei ihnen Äußerungen zu finden, die die Haltung gegenüber den Juden eingehender begründen wollen.

Feldwebel Christoph Banse, Jahrgang 1905, Angehöriger einer Transport-Kolonne der Luftwaffe, schreibt an seine Frau:

"Jetzt bin ich schon zwei Tage hier auf russischem Boden und morgen geht es wahrscheinlich wieder weiter ostwärts. Die Spuren des Krieges sind zum Teil sehr starke. In den Städten besteht die Bevölkerung meistens zu 50 bis 80 Prozent aus Juden. Da bekommt man einen Begriff von den Angehörigen des auserwählten Volkes. Die Juden sind es auch, die beim Begehen von Scheußlichkeiten an Ukrainern führend waren. Und mancher deutsche Soldat fiel der Hinterhältigkeit dieser Schmutzfinken zum Opfer. Wir Deutsche haben deshalb keinen Grund, mit diesen Kreaturen schonend umzugehen. Sie gelten deshalb augenblicklich nicht mehr soviel wie bei uns ein Hund. Für uns Soldaten ist das verständlich.« [7.7.1941]

Bei ihm hat also gleich zu Beginn die Indoktrinierung verfangen. Legt man Banses Zitat vom Juli 1941 zugrunde, wird man zu diesem Zeitpunkt sein weitgehendes Einverständnis mit der Ermordung von Juden annehmen können, die er hier als Revanche, in die er allerdings die ganze Volksgruppe einbezieht, zu rechtfertigen sucht.

Fast zwei Jahre später - er ist inzwischen Regierungs-Inspektor geworden schreibt er über die Rückfahrt von der Heimat nach Rußland:

»Der große Gegensatz zwischen unserer Welt und der Welt der Polen bot sich mir ja dann gleich als ich in die Gegend von Warschau kam. Diesen Unterschied zu schildern macht mir zuviel Mühe, und ich erzählte Dir ja schon davon, als ich im Frühjahr 1941 in diese schmucklose Welt verschlagen wurde. Aufgefallen ist mir, daß es keine Juden mehr hat. « [5.3.1943] 
Er nimmt im März 1943, einen Monat vor dem Aufstand im Warschauer Ghetto, das Verschwinden der Juden in der Umgebung wahr. Die Formulierung "aufgefallen ist mir« drückt dabei auch Überraschung aus. Wenn er etwas über Deportationen in Vernichtungslager wüßte, die seit Juli 1942 täglich über 10000 Menschen aus dem Ghetto betrafen, dann würde die Formulierung eine subtile Art der Verschleierung dieses Wissens seiner Frau gegenüber darstellen. So aber wirkt die Mitteilung wie die eines zwar oberflächlich Interessierten, aber nicht sonderlich nachfragenden Durchreisenden. Da es seine einzigen Äußerungen dazu bleiben, ist nicht zu klären, wieweit er etwas wußte und wissen wollte.

Propagandaformeln prägen auch die antisemitischen Briefpassagen von Heinz Heppermann, Jahrgang 1908. Er ist im Zivilberuf Lehrer. Mit dem Dienstrang eines Wachtmeisters bei der Nachrichten Abteilung 6 der 6 . Infanterie-Division befindet er sich im Sommer 1941 im Raum Witebsk, von November 1941 bis März 1943 im Raum Rshew. Obwohl er noch bis 1945 in den Bestandslisten der Wehrmachtauskunftsstelle verzeichnet und erst im März 1945 für tot erklärt wird, liegen von ihm nur Briefe bis zum März 1943 vor. Seine Briefe zeigen mehr als eine Übernahme, es ist eine Aneignung und Anreicherung der Propaganda mit den Eindrücken, die ihn zu Kriegsbeginn überwältigen. Die in der nationalsozialistischen Ideologie untrennbare Einheit von »bolschewistisch « und »jüdisch« fällt bei ihm von Anfang an auf fruchtbaren Boden und hilft ihm, die Komplexität der Eindrücke auf wenige Muster zu reduzieren. Brutalität der eigenen Seite wird nicht ausdrücklich erwähnt, aber vorsorglich gerechtfertigt mit dem Hinweis auf die Angst um die Heimat. Zusätzliche Legitimation zieht er aus dem Verhalten der Einheimischen, die die Deutschen zunächst freundlich in der Hoffnung auf Befreiung begrüßen und, folgte man dem Brief, die Besatzer erst zur Radikalität antreiben. Seiner Frau wird kaum eine Alternative bleiben, als seiner Darstellung zu folgen. Die erste Passage stammt aus dem »eigentlichen Rußland, und zwar kurz vor der Düna bei Polozk [...] von Moskau gesehen genau westlich “; die zweite schreibt er wenige Tage später weiter östlich, jetzt schon mit dem Blick Richtung Moskau, das aber »immerhin noch $600 \mathrm{~km}$ « entfernt ist. Da spürt er bereits die Reserviertheit der Bevölkerung. Sein Weltbild ist aber mächtig genug, sowohl die anfängliche Akzeptanz wie die Ablehnung zu interpretieren. Heppermann nimmt beides als Bestätigung für sein Feindbild:

"Wir denken oft mit Grauen an das Schicksal deutscher Frauen und Mädchen, wenn diese bolschewistischen Horden in ein Kulturland wie Deutschland eingebrochen wären! Diese Version ist einfach unausdenkbar! und Gott sei Dank, daß der Führer wieder im rechten Moment zupackte. Wenn Du diese Gestalten sehen wirst, von mongolischen Tartaren bis Kirgisen und Kalmücken, Du würdest dich abwenden! $\mathrm{Na}$, auch dieser Kampf ist einmal zu Ende. Wie lange oder wie schnell weiß ich natürlich auch nicht! Japan und Amerika scheinen ja auch allmählich in den Brand hineinzuschliddern! Es wird Zeit, daß diese jüdisch-bolschewistischen Welthetzer mit Stumpf und Stiel ausgerottet werden!

Im übrigen herrscht hier in Rußland das kommunistische System. Der einzelne besitzt beinahe nichts. Eine Kuh, ein wenig Acker für Gemüse; und wehe dem, der sich zusätzlich hätte bereichern wollen, ich meine, sein Gut zu vermehren suchte! Verbannung, Zwangsarbeit und Geldstrafen, Du kannst Dir vorstellen, daß diese geplagten Menschen unsere Ankunft in der Mehrzahl begrüßten. Die Frauen kamen und brachten uns ihre letzte Milch. Viel mehr besaßen sie ja nicht. Und die Fragen: Kommen die Bolschewiki zurück, bleibt ihr 
hier, vertreibt ihr die Machthaber (meistens Juden) noch weiter? Und wenn wir sagten, bis Moskau: >Dobsche, Dobsche‘, gut, gut, mit der bezeichnenden Halsabschneiderbewegung! « [17.7.1941]

„Wir liegen in einem kleinen russischen Städtchen (weit jenseits der Düna!) für einen Tag in Ruhe! [...] Diese Stadt ist wie alle russische Städte! Kleine, dunkle Holzhäuser, verkommene Menschen, arm, hungrig, wimmelnd von Kindern! Viele Häuser stehen leer: ausgerissene Juden oder Bolschewiken. Die Bevölkerung wird allmählich reservierter! Bolschewistische Propaganda!« [22.7.1941]

Seine Briefe zeigen in wenigen Andeutungen, daß die Grenzen zwischen dem militärischen Kampf, der Vernichtung von Partisanen und das Übergreifen der Herrschaftsmaßnahmen auf die Zivilbevölkerung verschwimmen:

"Ich weiß ja, wie Du immer auf Nachricht von mir wartest! Es ist hier immer noch das alte Lied! Der Mittelteil liegt in der Verteidigung. Wird aber wohl nicht lange mehr dauern. Ab und zu versucht der Russe durchzubrechen, allerdings ohne nachhaltigen Erfolg! Wenn auch mal eine Gruppe (100-200) durchdrücken, bzw. sich nächtlicher Weise durchschmuggeln, um besondere Aufträge durchzuführen, so dauert ihr Leben doch nicht allzu lange, da sie sich trotz Wälder und Sümpfe doch bald verraten. Bis zur Vernichtung ist dann kein langer Weg, besonders wenn die Artillerie oder Flak diese Herrschaften in direktem Beschuß erledigt. Viele Gefangene gibt es dabei nicht! Und manchmal nicht schöne Bilder! Die Zivilbevölkerung darf keine Verbindung mit diesen Partisanen halten; es [ist] ja auch richtig! Im anderen Falle droht der Strick! « [18.9.1941]

Wie ist dann folgende Mitteilung aus dem Herbst 1942 zu deuten?

"Was hier in unserer , Ecker wird, kann ich Dir nicht sagen. Ob es noch zu einem großen Schlag kommt ist ungewiß, zu wünschen wäre es ja. Besonders für den Winter. Unsere Angriffe (s. Wehrm.ber.) sind kleineren Ausmaßes und sollen die Ausmerzung etwaiger >Hautunreinigkeiten < bedingen. Wir sind im Augenblick nicht so sehr daran beteiligt.« [3.10.1942]

Warum versucht er eine eigene Beteiligung kleinzureden? Nur, um die Frau zu beruhigen, die ihn nicht in Gefahr sehen soll? Oder will er auch Distanz nehmen von einer Maßnahme, die er allerdings in einem Jargon beschreibt, der in der Sprache des »Dritten Reiches« die Grenzverwischung zwischen Partisanenbekämpfung und Antisemitismus nahelegt ${ }^{43}$ ?

Heppermann macht die Sprach- und Verständnislosigkeit, die ihn vereinsamen läßt, selbst zum Thema, wenn er kurz darauf schreibt:

43 In der untersuchten Stichprobe sind auch die Äußerungen über "Partisanen«- - insgesamt 20 - nicht besonders zahlreich. Es sind überwiegend kurze Bemerkungen, die von dem Bedrohungsgefühl der Soldaten zeugen, in einzelnen Fällen auch von Repressalien berichten: "Manchmal sieht man auch einen Gehängten. Das sind solche die sich am Eigentum des Hauses vergangen haben oder sich als Soldaten in Zivil in den Wäldern herumtrieben und Terrorakte verübten. Sie bleiben zur Abschreckung 2-3 Tage hängen. Sonst weiß ich keine Neuigkeiten mehr. [Alfred Vilsen, 16.9.1941]. Eine explizite Verbindung zum Themenkreis Juden - Antisemitismus ist in diesen Äußerungen nicht zu erkennen, wohl aber einzelne Versuche, die Partisanen von der 'gutmütigen ‘ armen $\mathrm{Zi}$ vilbevölkerung, die selbst als Opfer gesehen wird, zu unterscheiden. Daß die Hälfte der Mitteilungen über »Partisanen « auf den ältesten Schreiber der Gruppe entfällt (Otto Hilger, Jahrgang 1901), der in einer rückwärtigen Einheit im Raum Wilna und Gomel Dienst tut, weist darauf hin, daß bei gezielter standortspezifischer Suche auch deutlich mehr Aussagen zu diesem Thema in Feldpostbriefen zu erwarten sind. 
"Eins aber ist gewiß: wenn der Kampf einmal zu Ende sein wird, wird auch jene Bilanz,gezogen, die auch den Frontsoldaten bẻrücksichtigt und ihm sein volles Recht gewährleistet, mag er nun ordensgeschmückt sein oder eben nicht. [...] Der Mensch in der Heimat wird die Front nie begreifen, daher auch nicht ihre Leistung - auf der anderen Seite aber auch nicht ihr Elend und ihr Grausen. Welch eine Ausdauer schon für kultivierte Menschen Jahr um Jahr, im Sommer und Winter hier zu leben und auszuhalten: auch das versteht nicht der, der nicht dabei war. Du hast recht, viele haben >die Nase volk, jedem verständlich, der den Tag aushalten muß in Rußland; andererseits aber muß dieser Kampf ausgefochten werden als ein Kampf über allem anderen!« [29.10.1942]

So löst er das, was er vielleicht auch auf der Täterseite als unvermittelbar betrachtet, auf in dem allgemeinen Schmelztiegel von "Elend und Grausen «; im Brief an seine Frau stellt er sich als Opfer dar, um so mehr, als Anerkennung versagt bleibt. Anwandlungen des Zweifels steht ein 'jetzt erst recht ' gegenüber, das letztlich auch einer Radikalisierung in jedweder Richtung nichts entgegenzusetzen weiß.

Dem 21jährigen Hans Helmut Calsow, Leutnant beim Gebirgsjägerregiment 139, geht es in seinen Briefen an die Eltern vor allem gegen Ende um die Auseinandersetzung in ideologischen Fragen, wobei er offensichtlich auch unter dem Druck steht, sich zu rechtfertigen.

"Ja, meine lieben Eltern, ich bin heute durch und durch Nationalsozialist, ohne Einschränkung. Die paar Dinge, die mir nicht gefallen, kann ich nur beseitigen, wenn ich mitten drinstehe in der Bewegung. Sie fallen aber auch gar nicht ins Gewicht gegenüber dem Großen. Ihr seid Deutsche im früheren Sinn. Wir Deutschen haben eine Wandlung an uns vornehmen müssen, um der härteren anderen Welt widerstehen zu können, meiner Meinung ist der neue Deutsche der Nationalsozialist. « [7.7.1944]

Er hat allerdings ein Problem: Zwischen den Zeilen und nur in Abkürzungen geht er der Frage nach, ob sein Urgroßvater mütterlicherseits eventuell Jude war - er drängt auf Klärung, »denn es hängt doch etwas davon ab, nämlich mein persönliches Glück « - hier vermutlich in Verbindung mit seinen Aufstiegswünschen beim Militär. Die kognitive Dissonanz löst er in seiner Antwort auf einen Brief seiner Mutter, die ihn wohl zur Toleranz ermahnt hatte, so auf:

"U.G. ist für mich - ob er nun tatsächlich J. war oder nicht, ein ganz hervorragender Mensch gewesen und ich bin stolz darauf, ihn zu meinen Vorfahren zählen zu dürfen. Nein, um seine Person geht es hier gar nicht, es geht um das Große. [...] Meiner Meinung ist das Tolerante nicht der Inbegriff des Deutschen. Es war untrennbar vom früheren echten Deutschen, der Nationalsozialismus hat es nur mehr in kleinem Maße. Heute muß man auch - im Kleinen wie im Großen - viel absoluter sein als früher. Wir werden dazu von den Anderen gezwungen, die Beispiele fehlen nicht. Eines ist der Bombenkrieg. Wir Deutschen haben ihn nicht begonnen, der Führer hat $x$-Vorschläge dagegen gemacht. So mußte es zu V 1 kommen. Dasselbe ist es auch mit der J.- Frage. Warum haben wir den letzten Krieg verloren? Weil so ein paar Halunken in den Zeitungen so lange hetzten - im eigenen Land - , bis die Heimat umfiel. 33 war eben der Gegenschlag. Ich weiß genau, daß es unter den J. einige hervorragende Menschen gegeben hat, aber die Masse sind eben doch Schweinehunde. Wenn der Nationalsozialismus nicht gegen sie vorgegangen wäre, wäre es wohl nicht zu diesem Krieg gekommen - weil wir vorher bolschewisiert gewesen wären. Vielleicht ist es ein Zeichen der Minderwertigkeit, daß ich eine Sache so rückhalt- 
los bejahe. Es ist zweifellos auch leichter, als sich dagegen zu wehren im Strom. Mir ist aber die Entscheidung nicht gerade leicht gefallen. Ich liebe nun mal dieses Deutschland und bin bereit, ohne Rücksicht auf mein persönliches Wohlergehen meine Person voll und ganz dafür einzusetzen.« [7.7.1944]

Es ist kaum vorstellbar, daß ein Frontsoldat, der so mit den Eltern korrespondiert, nichts von Exzessen gegen die jüdische Bevölkerung mitbekommen haben sollte und hier nur eine abstrakte philosophische Diskussion führen möchte. Dennoch läßt sich aufgrund solcher Äußerungen noch nicht klären, wieweit die Schreiber im Einzelfall konkrete Kenntnis von Massenerschießungen und darüber hinaus auch von der Ermordung der Juden in eigens dafür geschaffenen Lagern hatten.

$\mathrm{Ob}$ man eine briefliche Schilderung der Beobachtung oder Beteiligung von Wehrmachtsoldaten bei Einsätzen gegen Juden allein aus Gründen der strengen Geheimhaltung nicht erwarten darf, ist fraglich, wenn man die offene Schilderung des Polizeiangehörigen Ludwig Eiber (s.o.) dagegenhält. Läßt sich dessen Bereitschaft zur Offenheit durch andere, abgemilderte Zensurerwartung erklären oder ist es doch die Massivität des Erlebens, verbunden mit der Überraschung des Neuen, die den Ausschlag gibt, ob etwas mitgeteilt wird? Zumindest in einer Zeit der ersten Begegnung, solange der Schreiber noch nicht die Prozesse der Gewöhnung oder Abspaltung des Nicht-Verarbeitbaren durchgemacht hat, scheint mir dies letzte eher zuzutreffen ${ }^{44}$.

Daß die Beobachter nicht, von den Ereignissen überschwemmt, ungefiltert ihre Beobachtungen schreiben, sondern abwägen; wo sie die Grenzen setzen, zeigt ein jetzt erschlossener Briefbestand des Hellfried H. ${ }^{45}$, Jahrgang 1923, Gefreiter bei der 293. Infanteriedivision (Polen, Weißrußland). Der Wert dieses Bestandes liegt darin, daß parallele Quellen desselben Schreibers vorliegen: Briefe, Notizen, Tagebücher und Berichte, die sein Vater nach seinen Erzählungen aufgezeichnet hat. So wird in Ansätzen erkennbar, wie er seine Mitteilungsbereitschaft in Abhängigkeit vom Medium gestaltet.

In den Briefen an seine Eltern beschreibt er im Juni 1941 das Ghetto in Litzmannstadt:

"Unglaublich sind die Zustände. Ein halbverfallenes Stadtviertel ist mit Stacheldraht abgezäunt wie ein Konzentrationslager, und dahinter das Volk in solchen Massen, daß sie sich bald zertreten. Damit sie auch über die Straße können, führen Holzbrücken von dem einen Fußsteig zum anderen. An jeder.Ecke ein Posten unter Gewehr. Wovon sie eigentlich leben, wissen wir nicht, jedenfalls versicherte der eine Posten, daß sie in ungeheuren Massen sterben.« [1.6.1941]

Anfang 1942 verwundet, gelangt er nach langem Lazarettaufenthalt und Urlaub wieder in den Osten. Im September 1942 kommt er zum Reserve-Infanterie-Bataillon 512 in Brest-Litowsk und wieder fällt ihm das Ghetto auf:

»Es ist ein sehr großes Ghetto hier, aber fast ohne Männer. Vor 14 Monaten wurden 5000 Männer zum >Arbeiten` weggeholt, sie sind seitdem verschwunden.

44 Um solche Entwicklungen einzuschätzen, müßten im einzelnen auch die Vorgeschichten der Briefschreiber vor allem in Polen und Serbien berücksichtigt werden, weil schon dort Prozesse der Gewöhnung sowie Abspaltungen dessen, was man nicht mitteilen konnte, stattgefunden haben.

45 Hellfried H., 130 Briefe, Tagebücher, sowie Aufzeichnungen seines Vaters nach Berichten des Sohnes. In Privatbesitz. Dank an Frau Helga H. für die freundliche Genehmigung. 
Die Juden erhalten nur $125 \mathrm{~g}$ Brot als tägliche Verpflegung, kein Fett. Kartoffeln können sie kaufen zu 1,20 RM das Kilo.« [20.9.1942]

Auch die anderen Merkmale eines Krieges im rückwärtigen Gebiet entgehen ihm nicht:

»Hier in der Gegend herrscht noch ziemliche Unruhe. Fast jede Nacht Sprengstoffattentate auf die Züge. Zu den Bauern aufs Land darf man sich hier nicht wagen, viele sind vom Organisieren nicht zurückgekommen. Ungefähr $20 \mathrm{~km}$ von hier liegen $3 \mathrm{Btl}$. Polizei in Stellung gegen Partisanen, SS-Truppen kommen von der anderen Seite, um diese aufzurollen. Dörfer werden abgebrannt, wo sich einer blicken läßt. « [20.9.1942]

Und dann, mit leichter, doch markanter Abweichung zwischen Tagebuch und Brief: »Erstmalig große Schießereien im Judenghetto. Mit der Zeit werden alle Juden erschossen.« [Tagebuch, 15.10.1942]

»In der letzten Woche hatten wir wieder Arbeit in Hülle und Fülle: Holzhacken, Mauern; Anstreichen usw. Vor allem müssen wir jetzt alle Arbeit allein machen. Seit wenigen Tagen ist nämlich das Ghetto menschenleer. Nachts Schießereien, tagsüber Abtransporte! Aber ich will darüber nichts weiter schreiben.« [Brief, 17.10.1942]

In der Menge seiner 130 Briefe und der Tagebücher gehen diese wenigen Notizen fast unter - und doch zeigen sie, wieviel eine gezielte (z.B. auf bestimmte Orte und Ereignisse bezogene) Suche nach Dokumenten von Zeitzeugen sowohl über die Breite des Wissens wie über die Modulation bei dessen Mitteilung zutage fördern können.

Auch sind diese Passagen aus dem Herbst 1942 ein Indiz dafür, daß meine aus der eigenen Untersuchung abgeleitete These hier nur als vorläufig gelten kann:

Es ist bemerkenswert, daß das Thema »Juden « in den Briefen der Soldaten insgesamt nur ein geringes, nach dem Sommer 1941 praktisch gar kein Gewicht hat, wobei Calsows ausführliche Stellungnahme vom Juli 1944 vor dem Hintergrund seiner persönlichen Betroffenheit die Ausnahme darstellt.

In den wenigen einschlägigen Zitaten findet sich ein Amalgam aus anfänglicher Reaktion auf ärmliche Lebensverhältnisse und propagandageleiteter Übernahme des Bildes vom "jüdisch-bolschewistischen « Feind. Die Äußerungen von Banse, Calsow, Heppermann, Leismeier und Nürnbach gehen in ihrer ausgeprägten Bejahung der antisemitischen Ideologie darüber hinaus. Bedeutsamer als Alters- und Adressatenunterschiede erscheint die Schichtzugehörigkeit: Banse, Calsow und Heppermann sind Unteroffiziere mit bürgerlich-akademischem Hintergrund. Sie untermauern ihre antisemitischen Äußerungen mit ideologischem Fundament. Leismeier und Nürnbach sind, was diese Gruppenzuordnung nach Dienstgrad und Schicht betrifft, Grenzfälle. Ihre Äußerungen markieren den Übergang zwischen einer reaktiven, spontan hochkochenden Bereitschaft, antisemitisches Gedankengut zu reproduzieren, und der ideologischen Verhärtung im Haß gegen die Juden.

Aber auch das andere bedarf der Erwähnung. Für die hier untersuchten Zeitabschnitte zwischen Juni 1941 und Herbst 1944 gilt: Obwohl nahezu alle Soldaten aus dem bürgerlich-akademișchen Milieu sich zu abfälligen, verächtlichen Bemerkungen über »primitive Verhältnisse« im besetzten Land bereit finden, äußert sich etwa die Hälfte von ihnen keinmal über die Juden; ebenso keiner der vier Soldaten aus dem landwirtschaftlichen Milieu (4 jüngere Gefreite bei kämpfenden Einheiten). Von den 9 Soldaten aus dem Umfeld Handwerk/kleine Angestellte 
äußern sich nur die zitierten Jolz und Vilsen (eher beschreibend) und Nürnbach, die anderen 6, überwiegend ältere Gefreite, die in rückwärtigen Einheiten eingesetzt sind, dagegen keinmal antisemitisch. Dies ist auffällig angesichts der Indoktrination durch die NS-Propaganda ab 1933 und vor dem Hintergrund; daß antisemitische Äußerungen keiner deutschen Zensur anstößig erschienen wären. Andererseits: Auch Anzeichen einer Protesthaltung gegenüber diesem Teil der NSIdeologie gibt es keine. Globale Äußerungen (»Mistkrieg «, und nur einmal: "Schuld", die man auf sich geladen habe ${ }^{46}$ ) sind zu unspezifisch, um sie mit dem Kampf gegen die Zivilbevölkerung und insbesondere die Juden in einen eindeutigen Zusammenhang zu bringen und als "Kritik" daran zu deuten.

Die Erklärung dafür, daß die Soldaten sich brieflich so wenig mit dem Schicksal der Juden in Rußland beschäftigten, und ab Herbst 1941 praktisch gar nicht, kann in sehr entgegengesetzte Richtungen gehen. Die traditionelle Erklärung würde lauten, daß die "Arbeitsteilung " zwischen dem Heer und den Einsatzgruppen von SD und SS spätestens nach den ersten Kriegsmonaten so >reibungslos` verlief, daß die meisten Soldaten von der Ermordung der Juden im besetzten Gebiet wenig mitbekamen. Eine andere Erklärung wäre, daß die Wahrnehmungsschwelle beim Einzelnen so hochgesetzt war, daß miterlebte verbrecherische Handlungen gar nicht bewußt bedacht, sondern sehr rasch verdrängt wurden oder der gesamte Themenkomplex unter äußeren und inneren Zensurvorbehalt fiel. Dagegen sprächen allerdings jene Einzelbelege aus Feldpostbriefen, die in der Literatur als Beweis für eine breite Verankerung des Antisemitismus angeführt werden und die vermuten lassen, daß an Orten, wo Wehrmachtsoldaten von der Vernichtung von Juden wußten, die Nachricht darüber zumindest in Spurenelementen auch in die Briefe einfloß. Nur aus einigen Briefen dieser Stichprobe spricht ein so krasser Antisemitismus, daß er bei den Schreibern ein grundsätzliches Einverständnis mit der systematischen Ermordung von Juden wahrscheinlich werden läßt.

Wenn ein Soldat sich im Privatbrief $z u$ einer das andere, das "Fremde " abwertenden, die eigene Kultur gleichzeitig herausstellenden Schreibweise gedrängt sieht, könnte darin nicht nur eine Vorbereitung für die ungehemmte Bereitschaft zur Vernichtung liegen, sondern vielmehr auch eine Antwort darauf, was er schon um sich herum erfährt und was so kraß von seinen Normen in der Vorkriegszeit abweicht? Das Provozierende an dieser Überlegung liegt darin, daß wir dann auch in mancher extremen antisemitischen Äußerung den Aufschein eines Gewissenskonflikts erkennen würden, der hier durch brieflichen Kontakt mit den nächsten Angehörigen in einen ideologischen Konsens und damit eine Entlastung überführt werden soll.

Bei vielen darf man eine allmähliche Gewöhnung und damit schleichende Akzeptanz judenfeindlicher Maßnahmen annehmen. Selbst wenn sie etwas nicht verstanden oder sogar inneren Widerwillen entwickelten, reichte es für die Herrschaftssicherung, wenn sie es als einen Teil der kriegsbedingten Notwendigkeiten ungefragt hinnahmen. Diejenigen, die von antijüdischen Maßnahmen etwas wußten, aber darüber schwiegen, leisteten damit ihren Beitrag zur Tabuisierung, die vielen in der Nachkriegszeit als Voraussetzung für eine gemeinsame kulturelle Basis des Wiederaufbaus erscheinen mochte.

Für jene, die das ganze Thema in ihren Briefen überhaupt nicht ansprachen, wird man schließlich auch die Hypothese aufstellen können, daß es sie einfach 
nicht "betraf", um die inhaltsanalytisch relevante Übersetzung von "concern« zu verwenden, auf den in Abhängigkeit vom Vorkommen eines Themas geschlossen wird. Das hieße: Sowohl in der ideologischen Zurüstung wie in der praktischen Herrschaftspolitik war Antisemitismus kein Thema, mit dem sie Berührung hatten oder suchten. Daß dies eine, nicht die einzige mögliche Erklärung sein kann, sollte deutlich geworden sein.

Was kam von alledem bei den Empfängerinnen und Empfängern in der Heimat an? Da, wo antisemitische Äußerungen, seien sie auch selten, in die Briefe einflossen, konnte dies gleichsam als eine 'Tröpfchen-Infektion` wirken. Die Angehörigen erfuhren (und übernahmen? ${ }^{47}$ ) die Anschauungen ihrer 'Zeugen vor Ortı, die ihnen in einer Flut von alltäglichen, für sie so nachvollziehbaren Mitteilungen (s.o.: die Standardthemen) in niedriger Dosierung, aber doch so hochpotenter Wirkung verabreicht wurden. Es mag sogar sein, daß die eher nebenbei erwähnte Abwertung des Feindes prägender wirkte als die lange argumentative Ausführung, weil der Gestus der selbstverständlichen Überlegenheit dann im Schreiben gleich mitgeliefert wurde. Wo sich die Soldaten kritisch von der eigenen Seite abgrenzen wegen der Länge und Härte des Krieges und seiner schwindenden Erfolgsaussichten, wegen erlebter Ungerechtigkeiten bei Beförderungen oder der täglichen Reibereien in der militärischen Zwangsgemeinschaft, werden die Angehörigen darin die wesentlichen Belastungen erkennen; das gleichzeitig vollständige Fehlen einer Kritik am antisemitischen Programm mag für die Familien zu Hause die Botschaft enthalten, daß der Angehörige im Felde davon nichts weiß, ja dies alles damit auch in seiner Umgebung gar keine Rolle spielt. Hierin liegt die bisher nicht erforschte Bedeutung der Feldpostbriefe für die Rezeption in der Nachkriegszeit: die Milliarden von Briefen als Medium der Selbstvergewisserung von Menschen, die sich als Opfer sehen und gegenseitig in dieser Rolle bestätigen, ohne ihre Täterseite wahrzunehmen.

47 Diese Frage verweist auf ein Desiderat der Forschung: Wie reagierten die Angehörigen? Die Archivbestände geben nur in den Einzelfällen Aufschluß, wenn auch Antwortbriefe gesammelt wurden. Sie erst gäben Hinweise auf die gemeinsame Konstituierung von Weltbildern und Verarbeitungen. Man darf von einem großen Vorkommen solcher >bilateralen Briefbestände < in privater Hand ausgehen. Vorsorglich ist für diesen Teil des Quellenmaterials, der sich vermutlich einer nächsten Forschungswelle erschließen wird, vor der willkürlichen Zitatenauswahl zum Beleg dieser oder jener These zu warnen. 


\section{Oldenbourg}

\section{Schriftenreihe der Vierteljahrshefte} für Zeitgeschichte im Abonnement: Nur DM 58,- statt 2 x DM 40,-

Band 80: Bert Hoppe Auf den Trümmern von Königsberg Kaliningrad 1946-1970

zum Inhalt Auf den Trümmern von Königsberg sollte eine sowjetische Stadt erstehen. Die neuen Machthaber tauschten die Bevölkerung aus, benannten die Stadt in Kaliningrad um und begannen mit einer radikalen architektonischen Umgestaltung, die selbst vor der Sprengung des Königsberger Schlosses nicht haltmachte. Bert Hoppe beschreibt und analysiert die Verzahnung von Architektur- und Identitätspolitik.

\section{Band 79: Susanna Schrafstetter Die dritte Atommacht}

Britische Nichtverbreitungspolitik im Dienst von Statussicherung und Deutschlandpolitik 1952-1968

zum Inhalt Der Besitz von Kernwaffen hatte für Großbritannien nicht nur militärische Bedeutung, sondern diente darüber hinaus der Erhaltung des Großmachtstatus. Dieses Interesse war auch die treibende Kraft der britischen Nichtverbreitungspolitik, die zu einem zentralen Aspekt der britischen Außenpolitik überhaupt wurde.

Ihre Bestellung richten Sie bitte an Ihren Fachbuchhändler oder direkt an: verkauf.f@verlag.oldenbourg.de
Herausgegeben vom Institut für Zeitgeschichte

2000.

166 Seiten

DM 40,-

ISBN 3-486-64580-3
1999.

254 Seiten, DM 40,ISBN 3-486-64579-X 